\title{
ANALYTICAL SOLUTIONS FROM BRUKER TO THE CRYSTALLOGRAPHY LABORATORIES
}

\author{
Adriana Parizatto Vieira*
}

Sales Coordinator AXS Division, Bruker do Brasil, Atibaia, São Paulo, Brasil

*adriana.parizatto@bruker.com

BRUKER is one of the biggest companies related to the analytical laboratory solutions worldwide. We have 4 divisions that are focused in different instruments to the main variety of applications of daily routine. One of these divisions is BRUKER MAT that factures all the products involved to the materials applications like X-Ray Fluorescence Spectrometer, X-Ray Diffraction, SEM and TEM detectors, Atomic Force Microscopes, Perfilometers and Tribology. The presentation is based in present an overview of this products showing the crystallography applications available, the instruments indicated for each material, the technology innovation over the years and the Bruker's differentials with his superior products. We have accessories for each application, bringing the most reliable results with easiest handling. BRUKER provides not just an instrument, but a solution for the laboratory studies. 